\title{
Contributory Factors to Hemorrhage After Ultrasound-Guided Fine Needle Aspiration of Thyroid Nodules with an Emphasis on Patients Taking Antithrombotic or Anticoagulant Medications
}

\author{
Jae Hyun Kwon, ${ }^{1,}$ Dae Bong Kim, ${ }^{1}$ Yoon Hee Han, ${ }^{1}$ Yoon Ki Cha,,${ }^{1}$ and Jeung Sook Kim ${ }^{1}$ \\ ${ }^{1}$ Department of Radiology, Dongguk University Ilsan Hospital, Dongguk University Graduate School of Medicine, Goyang-si, Gyeonggi-do, South Korea \\ "Corresponding author: Jae Hyun Kwon, Department of Radiology, Dongguk University Ilsan Hospital, Dongguk University Graduate School of Medicine, 27 Dongguk-ro, \\ Siksa-dong, Ilsandong-gu, Goyang-si, Gyeonggi-do, South Korea. Tel: +82-319617828, Fax: +82-319618281, E-mail: jhkwon17@naver.com \\ Received 2016 November 14; Revised 2017 July 17; Accepted 2017 September 10.
}

\begin{abstract}
Background: Thyroid nodules are a common clinical problem and ultrasound-guided fine needle aspiration (US-FNA) biopsy is widely used for evaluation of thyroid nodules. However, few studies have addressed the contributing factors to hemorrhage after US-FNA of thyroid nodules.

Objectives: To assess the contributory factors related to patient characteristics, ultrasound (US) features of the thyroid nodules, and the US-FNA procedures to affect hemorrhage complications after US-FNA of thyroid nodules.

Patients and Methods: Between March 2014 and April 2015, 366 consecutive patients who underwent US-FNA of thyroid nodules were enrolled in this retrospective study. The characteristics of hematomas, including the location, maximum size, and clinical course, were assessed. The relationships between hematomas and factors related to the medical characteristics of patients, US characteristics of the nodules, and FNA procedural factors were analyzed.

Results: Data on 365 nodules in 321 patients who underwent US-FNA of thyroid nodules were analyzed. Minor hemorrhagic complications developed in 14 (3.8\%) of the 365 nodules. There were no statistically significant differences between patients taking or not taking an anticoagulant or antithrombotic $(P=0.270)$. Factors related to increased risk of hematoma were male sex $(P=0.031)$, larger maximum size $(\mathrm{P}=0.002)$, a cystic or predominantly cystic nodule $(\mathrm{P}<0.0001)$, a probable benign nodule $(\mathrm{P}<0.0001)$, thicker needle size $(\mathrm{P}<0.0001)$, and a greater number of the needle passes $(\mathrm{P}=0.005)$.

Conclusion: US-FNA can be performed safely even in patients taking anticoagulant or antithrombotic agents. Factors related to hemorrhagic complications are male sex, larger nodules, cystic or predominantly cystic nodules, probably benign nodules, thicker needles and a greater number of needle passes.
\end{abstract}

Keywords: Thyroid Nodule, Ultrasound, Fine-Needle Aspiration, Hemorrhage, Complications

\section{Background}

Recently, thyroid nodules have been detected with increasing frequency as the use of ultrasound (US) has increased for evaluating the thyroid gland (1-3). US-guided fine needle aspiration (US-FNA) biopsy is a safe, accurate, and cost-effective method for the preoperative evaluation of thyroid nodules $(2,4-15)$. In addition, US is the most suitable method for evaluation of hemorrhagic complications after the procedure $(4,5)$. Minor hematomas and local pain are the most common clinical complications after US-FNA of thyroid nodules (4-6). However, few published studies have addressed the factors contributing to hematoma formation after US-FNA of thyroid nodules $(2,4-6,16)$. Additionally, performing US-FNA in patients taking anticoagu- lant or antithrombotic is controversial and lacking of evidence $(2,4,7,9,16-18)$.

\section{Objectives}

We retrospectively reviewed contributing factors to hematoma formation after US-FNA of thyroid nodules. Specifically, we considered factors related to baseline characteristics of the patients, to US characteristics of the thyroid nodules, and to US-FNA procedures.

\section{Patients and Methods}

Institutional review board approval was obtained for this retrospective research and the need for informed con- 
sent was waived because of the retrospective nature of the study.

\subsection{Patients}

We reviewed the procedures and imaging findings of all patients who underwent US-FNA biopsy of a thyroid nodule between March 1, 2014, and March 31, 2015. Data were collected by review of electronic medical records and questionnaires obtained in the US room before US-FNA of thyroid nodules. Patients who underwent US and US-FNA biopsy of a thyroid nodule and who completed the questionnaire before US and US-FNA biopsy were included. The patient's questionnaire included previous medical history (hypertension, chronic renal failure, chronic liver disease, hemophilia and other coagulopathic diseases), status of thyroid function (hyperfunction, euthyroid status, hypofunction, and de Quervain thyroiditis) and medication history of anticoagulant and antithrombotic agents. Patients who underwent US-FNA for lesions in the thyroid bed after a partial or total thyroidectomy were excluded. Bleeding parameters, such as platelet count, prothrombin time international normalized ratio(PT INR), and activated partial thromboplastin time (aPTT), were not routinely measured or considered in the decision process for US-FNA.

\subsection{Ultrasonography}

All US examinations were performed with an iU22 (Philips Ultrasound, Bothell, WA, USA) US system using a 5 - $12 \mathrm{MHz}$ linear-array transducer. Three radiologists (J.H.K., D.B.K., Y.H.H.) with 9, 7, and 5 years of clinical experience, respectively, performed US and US-FNA to diagnose thyroid nodules in consecutive patients on an outpatient basis. The US-FNA was performed several days later after US of the thyroid nodule. During the study period, the patients did not take their anticoagulant and antithrombotic medication before the US-FNA.

The US findings and characteristics of the nodules were obtained from the clinical reports, which were initially reported by one of the three radiologists who also performed US-FNA of the nodules. Maximum size was defined as the longest diameter of the nodule in any direction and any scan plane. The location of the nodule was classified as the right, isthmic, and left lobe of the thyroid gland. Probably benign gray-scale US features were classified using previously published criteria of a pure cystic or spongiform appearance of the nodule. Suspicious malignant gray-scale US features were marked hypoechogenecity, taller-thanwide shape, showing microcalcifications or macrocalcifications, and having spiculated or microlobulated margins. Indeterminate nodules included those with US findings with neither malignant nor benign features (3). The internal content of a nodule was categorized according to the ratio of the cystic portion to the solid portion, as reported previously (3). Heavy calcification was defined as calcification occupying more than $90 \%$ of the nodule. All thyroid nodules undergoing FNA were examined by color Doppler US before US-FNA was performed. The intra-nodular, peripheral nodular, and parenchymal vascularity were categorized into three types each, modified from previous reports (19-23). Intra-nodular vascularity was defined as type 1 (no color Doppler flow within the nodule), type $2(<50 \%$ of the area of the nodule), and type 3 (intra-nodular flow defined as $\geq 50 \%$ of the area of the nodule). Peripheral vascularity was defined as type 1 (no color Doppler flow in the periphery of the nodule), type 2 (a peripheral ring of flow defined as $<50 \%$ of the nodule's circumference), and type 3 (a peripheral ring of flow defined as $\geq 50 \%$ of the nodule's circumference). Three types of parenchymal vascularity were defined: type 1 (no color Doppler flow in the parenchyma of the thyroid gland), type 2 (parenchymal flow defined as $<50 \%$ of the parenchyma), and type 3 (parenchymal flow defined as $\geq 50 \%$ of the parenchyma).

\subsection{US-Guided FNA Biopsy}

The indications for US-FNA of a thyroid nodule were the same as those described previously (3). Informed consent for US-FNA was obtained from before each procedure. US-FNA was performed according to recommendations for thyroid nodules $(3,8,11,12,24,25)$. Factors related to USFNA procedure, such as diameter of the needle, the pass number of the needle per one nodule, whether performing fluid aspiration just before US-FNA, application of the suction during US-FNA were assessed to reveal the relationship with hemorrhagic complication.

The FNA biopsy was performed with the patient supine, using a high-resolution 5 - $12 \mathrm{MHz}$ linear-array transducer. After the lesion was localized, the overlying skin was cleansed with a $10 \%$ povidone-iodine and absolute ethanol. Local anesthesia was not used. A 21- to 25-gauge needle was used with and attached to a $5-10 \mathrm{~mL}$ syringe (syringe-needle unit) without an aspiration device. The sampling was performed using the capillary sampling technique (non-aspiration) or suction applied technique (aspiration). The choice between the capillary sampling and aspiration techniques was determined according to operator preference. When the needle tip was placed appropriately within the target nodule, a tissue sample was obtained with six or seven "to-and-fro" needle movements over 5 - 10 seconds. The number of needle passes ranged from 2 - 4 for each nodule depending on the US characteristics of the thyroid nodule. For cystic or complex nodules, the FNA biopsy was performed in the solid portion without aspiration of cystic fluid. However, cystic fluid was aspirated before the FNA biopsy if the solid portion was 
too small to obtain tissue material. The specimen was prepared by a liquid-based cytology technique(CytoRich ${ }^{\circledR}$, TriPath Imaging, Inc., Burlington, NC, USA).

At the same time the procedure was completed, the operator performed US of the neck to evaluate any hemorrhagic complications. If no hemorrhagic complication was noted, the puncture site was compressed manually for 10 minutes in patients without bleeding diathesis and for 20 - 30 minutes in patients with bleeding diathesis. After compression, if there was no sign of bleeding-related complications, the patient was then discharged. In patients who developed hemorrhagic complications after US-FNA of the thyroid nodule, the puncture site was compressed manually for 10 minutes, after which it was then reexamined by US. If there were no changes or minor changes in the size or extent of the hemorrhage on reexamination, the patient was discharged. If there were any changes that may result in major hemorrhagic complications on reexamination, the patient was hospitalized and managed appropriately $(2,5)$.

\subsection{Hemorrhagic Complications}

Major hemorrhagic complications were defined as hematomas requiring prolonged hospitalization or interventions. Other hemorrhagic complications not requiring prolonged hospitalization or interventions were classified as minor hemorrhagic complications. The type of complication after US-FNA was classified as intra-nodular, parenchymal, subcapsular, and extracapsular according to the location of the hematoma. In patients with complications after US-guided FNA, the size of the hematoma was checked just after the procedure (height $\times$ width $\times$ depth $\mathrm{cm})$.

\subsection{Statistical Analysis}

To evaluate the relationship between variables and hemorrhagic complications, Student's unpaired t-test (Wilcoxon's rank sum test) was used for continuous variables and the $\chi^{2}$ test was used for categorical variables. Unadjusted and adjusted multiple logistic regression analysis was used to estimate associations between variables and hemorrhagic complications. Odds ratios (ORs) and 95\% confidence intervals (CIs) were calculated for variables that showed statistically significant differences in student's unpaired t-tests (Wilcoxon's rank sum tests) and $\chi^{2}$ tests. A P value $<0.05$ was considered to indicate statistical significance. Statistical analyses were performed using SAS software (ver. 9.3; SAS Institute Inc., Cary, NC, USA).

\section{Results}

\subsection{Patient Characteristics and US Features of Thyroid Nodules}

US-FNA was performed in 366 consecutive patients during the study period. Of the 366 patients, 30 did not complete the questionnaire, and in 15 patients, US-FNA was performed for nodular lesions on the thyroid bed after total or hemi-lobectomy of the thyroid gland; these patients were excluded. Data analysis was performed for 365 nodules in 321 patients. The baseline medical characteristics of the patients are summarized in Table 1 . Of the 321 patients, 122 had one nodule, 80 had two nodules, 35 had three nodules, 16 had four nodules, 11 had five nodules, and 58 had more than five nodules. Vascularity data were unavailable for 13 nodules in which Doppler US was not performed prior to USFNA. Of the 321 patients, 36 patients underwent US-FNA for more than two nodules at the same session. Of these 36 patients, 29 underwent US-FNA for more than two nodules in the right, left, or isthmic lobe, 5 patients in the right lobe, and 4 patients in the left lobe. Of the 321 patients, 6 underwent US-FNA for the same thyroid nodules at 3 to 4 - month intervals. Adequate specimens were observed in 330 of the 365 nodules (90.4\%).

\begin{tabular}{|c|c|}
\hline Variables & Value \\
\hline Mean age (range) & $51.4(17-90)$ \\
\hline \multicolumn{2}{|l|}{ Sex } \\
\hline Female & 258 \\
\hline Male & 63 \\
\hline \multicolumn{2}{|l|}{ Previous medical history } \\
\hline Hypertension & 67 \\
\hline Chronic renal failure & 1 \\
\hline \multicolumn{2}{|l|}{ Thyroid function test } \\
\hline Hyperfunction & 16 \\
\hline Euthyroid & 178 \\
\hline Hypofunction & 14 \\
\hline Not available & 113 \\
\hline \multicolumn{2}{|l|}{ Medication } \\
\hline Antithrombotic & 25 \\
\hline Anticoagulant & 2 \\
\hline Antithrombotic + anticoagulant & 4 \\
\hline
\end{tabular}

\subsection{Complications}

No major hemorrhagic complications developed in any patient who underwent US-FNA of thyroid nodules in this study. Minor complications developed in 14 (3.8\%) 
of the 365 nodules after US-FNA. The locations of the hematomas were as follows: five in intra-nodular locations (Figure 1), four in parenchymal locations (Figure 2), four in subcapsular locations (Figure 3), and one in an extracapsular (skin hemorrhage) location. The maximum size of the hematomas ranged from 1 to $3 \mathrm{~cm}$ (mean, $1.5 \mathrm{~cm}$ ) immediately after the end of the US-FNA. After manual compression of the puncture site for 10 minutes, the sizes of the hematomas ranged from 1 to $3.6 \mathrm{~cm}$ (mean, $1.7 \mathrm{~cm}$ ). No additional manual compression was applied in these 14 patients because no other treatment was required for hemorrhagic complications. These 14 patients who developed minor hemorrhagic complications did not complain any symptoms related to hemorrhagic complication on follow up of out-patient department in 5 to 10 days after the biopsy. And also, those remaining patients who did not developed hemorrhagic complications immediately after the US-FNA showed no symptoms related to hemorrhagic complication on follow up during same periods.

\subsection{Patient Characteristics and Hemorrhagic Complications}

The relationships between the baseline characteristics of patients and hemorrhagic complications after US-FNA of thyroid nodules are summarized in Table 2. The incidence of hemorrhagic complications was significantly higher in males than females $(\mathrm{P}=0.031)$, as well as in patients with, compared to those without, chronic renal failure $(P=0.038)$. No statistical significance was noted in terms of hypertension, status of the thyroid function, and administration of antithrombotics or anticoagulants.

\subsection{US Characteristics and Hemorrhagic Complications}

The relationships between US characteristics of nodules and hemorrhagic complications after US-FNA of thyroid nodules are summarized in Table 3. The mean and median diameter of the nodules with hemorrhagic complications were significantly larger than those of nodules without complications $(\mathrm{P}=0.002)$. Hemorrhagic complications were significantly higher in predominantly cystic nodules $(\mathrm{P}<0.0001)$, probably benign nodules $(\mathrm{P}<$ $0.0001)$, nodules with type 1 intra-nodular vascularity $(\mathrm{P}=$ $0.005)$ and nodules with type 1 peripheral vascularity $(\mathrm{P}=$ 0.005). Other US features, such as the location of the nodules, heavy calcification, and the type of parenchymal vascularity on Doppler US, did not show any statistical significance in terms of hemorrhagic complications.

\subsection{US-FNA and Hemorrhagic Complications}

The relationships between factors related to US-FNA of thyroid nodules and hemorrhagic complications are summarized in Table 4. Hemorrhagic complications were significantly higher when using a $21 \mathrm{G}$ needle $(\mathrm{P}<0.0001)$,
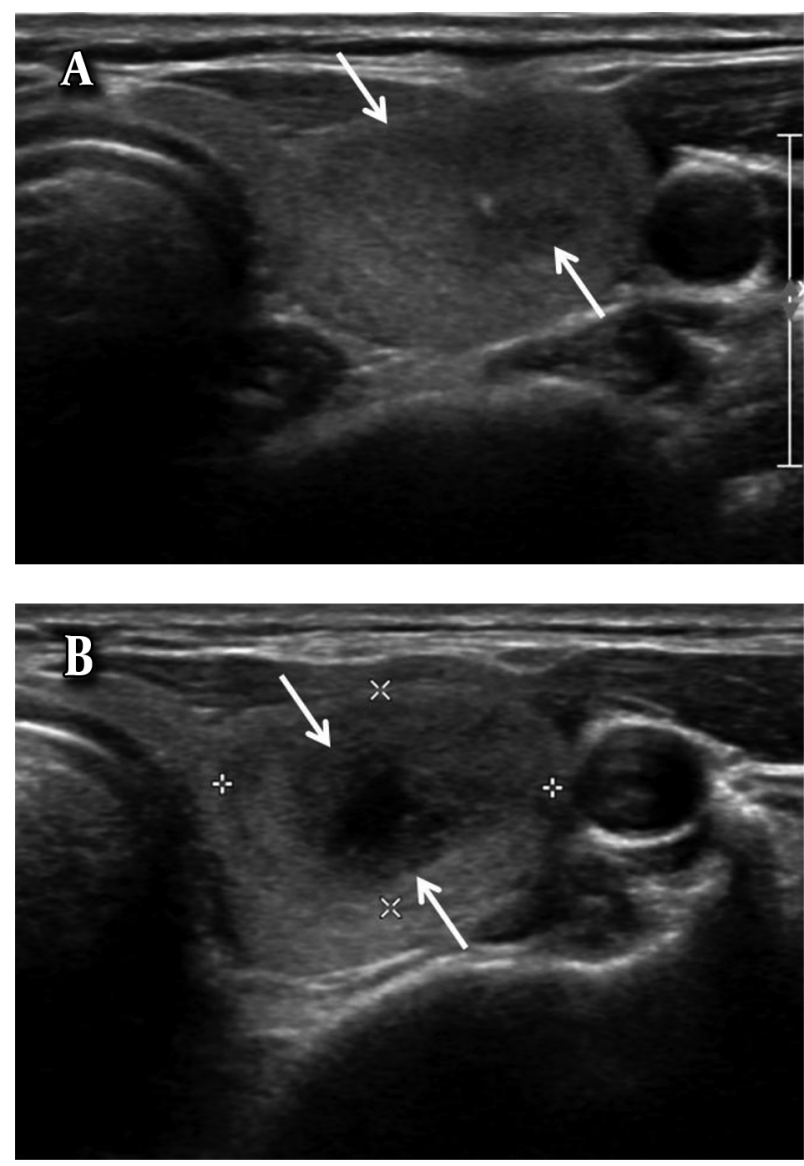

Figure 1. A 43-year-old woman with an intranodular hematoma. A, Axial ultrasonography image shows a hypoechoic solid nodule (arrows) in the left lobe of the thyroid gland. B, Axial ultrasonography image of the nodule after ultrasound-guided fine needle aspiration (US-FNA) shows an anechoic area (arrows) in the central portion of the nodule, suggesting an intranodular hematoma.

with four passes of the needle $(\mathrm{P}=0.005)$, in cystic and predominantly cystic nodules in which fluid aspiration was not performed $(\mathrm{P}<0.0001)$. The hemorrhagic complication rate was not significantly different between nodules where suction was applied or not during US-FNA $(\mathrm{P}=0.255)$.

Multiple logistic regression analyses of the association between hemorrhagic complications and the variables showing statistically significant differences in student's unpaired t-tests and $\chi^{2}$ tests are summarized in Table 5 . Hemorrhagic complications were higher in males, in larger nodules, in predominantly cystic nodules (and a trend of decreased incidence in predominantly cystic, cystic, predominantly solid, and solid nodules in that order; $\mathrm{P}<0.0001$ and $\mathrm{P}=0.004$ in unadjusted and adjusted models, respectively), and when a $20 \mathrm{G}$ needle was used (and a decreasing trend for $21 \mathrm{G}, 22 \mathrm{G}$, and $25 \mathrm{G}$ needles in that order; $\mathrm{P}<0.0001$ and $\mathrm{P}=0.020$ in unadjusted and 


\begin{tabular}{|c|c|c|c|}
\hline \multirow[t]{2}{*}{ Variables } & \multicolumn{2}{|c|}{ Hemorrhagic Complications } & \multirow[t]{2}{*}{ Pvalue } \\
\hline & Positive, $N=14$ & Negative, $N=351$ & \\
\hline Gender & & & 0.031 \\
\hline Female & $8(2.7)$ & $284(97.3)$ & \\
\hline Male & $6(8.2)$ & $67(91.8)$ & \\
\hline Hypertension & & & 0.257 \\
\hline Negative & $11(3.9)$ & $275(96.2)$ & \\
\hline Positive & $3(3.8)$ & $76(96.2)$ & \\
\hline Chronic renal failure & & & 0.038 \\
\hline Negative & $13(3.6)$ & $351(96.4)$ & \\
\hline Positive & $1(100)$ & $0(0)$ & \\
\hline TFT & & & 0.251 \\
\hline Hypofunction & $0(0)$ & $17(100)$ & \\
\hline Euthyroid & $9(4.3)$ & $200(95.7)$ & \\
\hline Hyperfunction & $0(0)$ & $17(100)$ & \\
\hline Unavailable & 5 & 117 & \\
\hline AC and/or AT & & & 0.270 \\
\hline Taking & $0(0)$ & $36(100)$ & \\
\hline Not taking & $14(4.3)$ & $315(95.7)$ & \\
\hline
\end{tabular}

Abbreviations: AC, Anticoagulant; AT, Antithrombotic; TFT, Thyroid function test. ${ }^{\mathrm{a}}$ Values are expressed as No. (\%).

adjusted models, respectively). The hemorrhagic complication showed increasing trend as greater the number of needle pass times although not statistically significant $(P$ $=0.172$ and $\mathrm{P}=0.895$ in unadjusted and adjusted models, respectively).

\section{Discussion}

US-FNA of thyroid nodules is a simple, minimally invasive, and safe procedure, usually performed in the outpatient clinic (2). The most common complications are local pain or discomfort and minor hematomas $(4,6)$. The incidence of hematoma ranges from $0 \%$ to $6.4 \%$ in different studies (4). In this study, the incidence of hematoma was $3.8 \%$ (14 of 365 nodules) with no major complications with a self-limiting course. This is consistent with results of previously reported studies during or after US-FNA, of which all were minor hematomas (4, 6, 26-29).

Few studies have addressed factors related to hemorrhagic complications after US-FNA of thyroid nodules $(4,6$, 16). The most likely mechanism for thyroid hemorrhage after FNA is thought to be venous bleeding into or around the nodules $(30,31)$. Factors that facilitate susceptibility to hemorrhagic complications after US-FNA include straining, hypertension, a sudden reduction in intra-nodular pressure soon after fluid aspiration in a cystic nodule, severe bleeding diathesis, and medication with anticoagulant or antithrombotic $(4,6,32)$.

Among the variables in baseline characteristics, males and patients with chronic renal failure showed statistically higher hemorrhagic complication rates. It is difficult to explain why the incidence of hemorrhage was higher in males than females. Hypertension did not affect the incidence of hemorrhagic complications. It has been recommended that in cases of hyperthyroidism or De Quervain's thyroiditis, FNA should be delayed until euthyroid restoration $(4,6)$. However, there were no significant differences in the incidence of hemorrhage between patients presenting with hyper-function, hypo-function, or euthyroid status.

Before US-FNA of thyroid nodules, any medical history of diseases affecting the coagulation cascade (chronic liver disease, end-stage renal disease, hematological disease), and anticoagulant or antithrombotic medications should be evaluated $(5,6)$. In the present study, one patient with chronic renal failure developed hemorrhagic complications. If the patient is taking an anticoagulant or an- 


\begin{tabular}{|c|c|c|c|}
\hline \multirow[t]{2}{*}{ Variables } & \multicolumn{2}{|c|}{ Hemorrhagic Complications } & \multirow[t]{2}{*}{ Pvalue } \\
\hline & Positive, $N=14$ & Negative, $N=351$ & \\
\hline Location & & & 0.558 \\
\hline Right & $9(4.8)$ & $180(95.2)$ & \\
\hline Left & $5(3.0)$ & $160(97.0)$ & \\
\hline Isthmus & $0(0)$ & $11(3.1)$ & \\
\hline Max size, $\mathrm{cm}$ & & & 0.002 \\
\hline Mean \pm SD & $2.7 \pm 1.3$ & $1.8 \pm 1.2$ & \\
\hline Median (Min, Max) & $2.50(1.1,5.8)$ & $1.50(0.3,7.4)$ & \\
\hline Content & & & $<0.0001$ \\
\hline Cystic & $3(17.7)$ & $14(82.4)$ & \\
\hline Predominantly cystic & $9(22.5)$ & $31(77.5)$ & \\
\hline Predominantly solid & $1(1.5)$ & $66(98.5)$ & \\
\hline Solid & $1(0.4)$ & $239(99.6)$ & \\
\hline Benign vs. malignant & & & $<0.0001$ \\
\hline Probably benign & $3(23.1)$ & $10(76.9)$ & \\
\hline Indeterminate & $10(4.2)$ & $227(95.8)$ & \\
\hline Suspicious malignant & $1(0.9)$ & $114(99.1)$ & \\
\hline Heavy calcification & & & 0.385 \\
\hline Positive & $1(4.6)$ & $21(95.5)$ & \\
\hline None & $13(3.8)$ & $330(96.2)$ & \\
\hline Intra-nodular vascularity on Doppler US & & & 0.005 \\
\hline Type 1 & $6(7.8)$ & $71(92.2)$ & \\
\hline Type 2 & $7(3.4)$ & $202(96.7)$ & \\
\hline Type 3 & $0(0)$ & $66(100)$ & \\
\hline Peripheral vascularity on Doppler US & & & 0.045 \\
\hline Type 1 & $3(5.6)$ & $51(94.4)$ & \\
\hline Type 2 & $6(3.9)$ & $150(96.2)$ & \\
\hline Type 3 & $4(2.8)$ & $138(97.2)$ & \\
\hline Parenchymal vascularity on Doppler US & & & 0.079 \\
\hline Type 1 & $2(5.4)$ & $35(94.6)$ & \\
\hline Type 2 & $9(3.5)$ & $251(96.6)$ & \\
\hline Type 3 & $2(3.7)$ & $53(96.4)$ & \\
\hline
\end{tabular}

Abbreviation: SD, Standard deviation; US, Ultrasound.

${ }^{\mathrm{a}}$ Values are expressed as No. (\%).

${ }^{\mathrm{b}}$ Type 1, no vascularity; Type 2, mild vascularity (<50\%); Type 3, moderate vascularity ( $\geq 50 \%$ ).

tithrombotic, stopping the medication for 3-10 days is recommended before and after US-FNA (4, 5, 9, 11, 17, 18). However, performing US-FNA in patients taking anticoagulant or antithrombotic remains controversial and lacking in evidence, such as randomized controlled study $(2,4,7,9,16$, 33). A recent study of 593 patients who underwent US-FNA on a total of 788 neck lesions reported no significant differences in hematoma formation between patients who were on antithrombotic medications and those who were not (16). In the present study, no hemorrhagic complication developed in patients taking anticoagulant or antithrombotic during US-FNA. Thus, we suggest that US-FNA of thy- 


\begin{tabular}{|c|c|c|c|}
\hline \multirow[t]{2}{*}{ Variables } & \multicolumn{2}{|c|}{ Complication Rate } & \multirow[t]{2}{*}{ Pvalue } \\
\hline & Positive, $N=14$ & None, $N=351$ & \\
\hline Needle size & & & $<0.0001$ \\
\hline $25 \mathrm{G}$ & $4(1.6)$ & $250(98.4)$ & \\
\hline $22 \mathrm{G}$ & $7(6.5)$ & $101(93.5)$ & \\
\hline $21 \mathrm{G}$ & $3(100)$ & $0(0)$ & \\
\hline Pass number & & & 0.005 \\
\hline 2 & $6(7.7)$ & $72(92.3)$ & \\
\hline 3 & $7(2.5)$ & $275(97.5)$ & \\
\hline 4 & $1(20)$ & $4(80)$ & \\
\hline Fluid aspiration $(n=57)$ & & & $<0.0001$ \\
\hline Non-aspiration & $11(29.7)$ & $26(70.3)$ & \\
\hline Aspiration & $1(4.8)$ & $20(95.2)$ & \\
\hline Suction & & & 0.255 \\
\hline Suction applied & $12(3.7)$ & $318(96.4)$ & \\
\hline Capillary sampling & $2(5.7)$ & $33(94.3)$ & \\
\hline
\end{tabular}

${ }^{\mathrm{a}}$ Values are expressed as No. (\%).

roid nodules can be performed safely in patients who are taking antithrombotic or anticoagulant without stopping the medications without the increased risk of cardiac or thromboembolic events (16). Additionally, the procedure may reduce patient time and expense by eliminating repeated clinic appointments and may also reduce the time interval between diagnosis and treatment (16). However, US-FNA should be performed carefully in patients taking anticoagulants or antithrombotics, using the smallest needle possible, a limited number of passes, and a longer period of pressure application because hemorrhagic complications compressing the upper airway may occur, although rare $(5,30,31,34)$.

Among the variables in US characteristics of the thyroid nodules, predominantly cystic or cystic internal content and probably benign or indeterminate nodules were related to higher rates of hemorrhagic complications. It is difficult to explain the relationship between the incidence of hemorrhagic complications and these US features. In terms of vascularity, the complication rate was significantly higher in nodules showing type 1 intra-nodular and type 1 peripheral vascularity. The complication rate was not significantly different between nodules showing a different type in parenchymal vascularity. According to the results of our study, it appears that US-FNA can be performed safely even for nodules showing high vascularity.

Hemorrhagic complications after US-FNA were more frequent when using thicker needles $(6,8,10)$. In this study, hemorrhagic complications were significantly lower with $25 \mathrm{G}$ than $22 \mathrm{G}$ or $21 \mathrm{G}$ needles. Thus, starting FNA using a thinner needle is recommended and thicker needles should generally be reserved for draining viscous colloid cysts. Generally, two to five passes seem reasonable to ensure an adequate sample (2, 35-37). Our results show that the incidence of hemorrhagic complications increased with an increase in the number of passes. In previous studies, there were no statistically significant differences between the capillary sampling technique and FNA with suction with regard to diagnostic accuracy (37-40). In our study, the hemorrhage complication rate was not significantly different between the two techniques. Hence, the choice between the capillary sampling technique and FNA with suction may depend on operator preference $(5,9,41)$. If a nodule is largely cystic or predominantly cystic, sampling should be done in the residual solid component after aspiration of the fluid component $(5,11,37)$. Hemorrhage may occur soon after fluid aspiration, probably as a result of the sudden reduction in intra-nodular pressure (42). Braga et al. (32) reported a high rate of hemorrhage within the cavity when performing aspiration of cystic fluid before US-FNA of thyroid nodules, whereas other studies have reported no hemorrhagic complications when performing fluid aspiration $(6,26)$. Our results show that hemorrhagic complications were higher in cystic and predominantly cystic nodules which cystic fluid was not aspirated before US-FNA. 


\begin{tabular}{|c|c|c|c|c|}
\hline Variables & Unadjusted OR (95\% CI) & Pvalue & Adjusted OR(95\% CI) & Pvalue \\
\hline \multicolumn{5}{|l|}{ Sex } \\
\hline Female (ref.) & 1 & & 1 & \\
\hline Male & $3.179(1.067-9.469)$ & & $4.302(0.684-27.050)$ & \\
\hline Max size $($ mean $\pm S D$ cm $)$ & $1.581(1.126-2.22)$ & & $1.042(0.491-2.210)$ & \\
\hline Content & & $<0.0001$ & & 0.004 \\
\hline Cystic (ref.) & 1 & & 1 & \\
\hline Predominantly cystic & $1.355(0.317-5.781)$ & & $1.154(0.153-8.735)$ & \\
\hline Predominantly solid & $0.071(0.007-0.731)$ & & $0.050(0.002-1.009)$ & \\
\hline Solid & $0.020(0.002-0.200)$ & & $0.017(<0.001-0.413)$ & \\
\hline Benign vs. malignant & & 0.002 & & 0.303 \\
\hline Probably benign (ref.) & 1 & & 1 & \\
\hline Indeterminate & $0.147(0.035-0.618)$ & & $0.113(0.012-1.059)$ & \\
\hline Suspicious malignant & $0.029(0.003-0.308)$ & & $0.125(0.005-3.461)$ & \\
\hline \multicolumn{5}{|l|}{ Vascularity } \\
\hline Intranodule & & 0.369 & & 0.115 \\
\hline Type 1 (ref.) & 1 & & 1 & \\
\hline Type 2 & $0.410(0.133-1.261)$ & & $2.469(0.253-24.084)$ & \\
\hline Type 3 & $<0.001(<0.001->999.999)$ & & $0.001(<0.001->999.999)$ & \\
\hline Periphery of nodule & & 0.016 & & 0.253 \\
\hline Type 1 (ref.) & 1 & & 1 & \\
\hline Type 2 & $0.680(0.164-2.818)$ & & $0.696(0.069-6.990)$ & \\
\hline Type 3 & $0.493(0.107-2.278)$ & & $3.337(0.243-45.773)$ & \\
\hline Needle size & & $<0.0001$ & & 0.020 \\
\hline $25 \mathrm{G}$ (ref.) & 1 & & 1 & \\
\hline $22 \mathrm{G}$ & $4.332(1.241-15.119)$ & & $8.292(1.227-56.049)$ & \\
\hline $21 \mathrm{G}$ & $>999.999(<0.001->999.999)$ & & $>999.999(<0.001->999.999)$ & \\
\hline Pass number & & 0.172 & & 0.895 \\
\hline 1 (ref.) & 1 & & 1 & \\
\hline 2 & $0.305(0.100-0.937)$ & & $2.008(0.271-14.883)$ & \\
\hline 3 & $3.000(0.288-31.276)$ & & $<0.001(<0.001->999.999)$ & \\
\hline Fluid aspiration & & 0.003 & & 0.103 \\
\hline Non-aspiration & 1 & & 1 & \\
\hline Aspiration & $0.112(0.025-0.412)$ & & $0.093(0.009-1.049)$ & \\
\hline
\end{tabular}

Abbreviations: $\mathrm{CI}$, confidence interval; OR, odds ratio; ref., Reference; SD, standard deviation

${ }^{\mathrm{a}}$ Type 1, no vascularity; Type 2 , mild vascularity ( $<50 \%$ ); Type 3 , moderate vascularity ( $\geq 50 \%$ ).

The multiple logistic regression analysis in the present study indicated that hemorrhagic complications were higher in males, in larger nodules, in predominantly cystic nodules and when the thicker needle was used. Hemorrhagic complications showed increasing trend as the greater the number of the needle passes.
There were several limitations to our study. First, it was performed retrospectively, so a prospective randomized controlled study is needed to examine the relationships between hemorrhagic complications and the variables reported on herein. Second, no routine screening tests for coagulation parameters such as platelet count, PT INR, or 

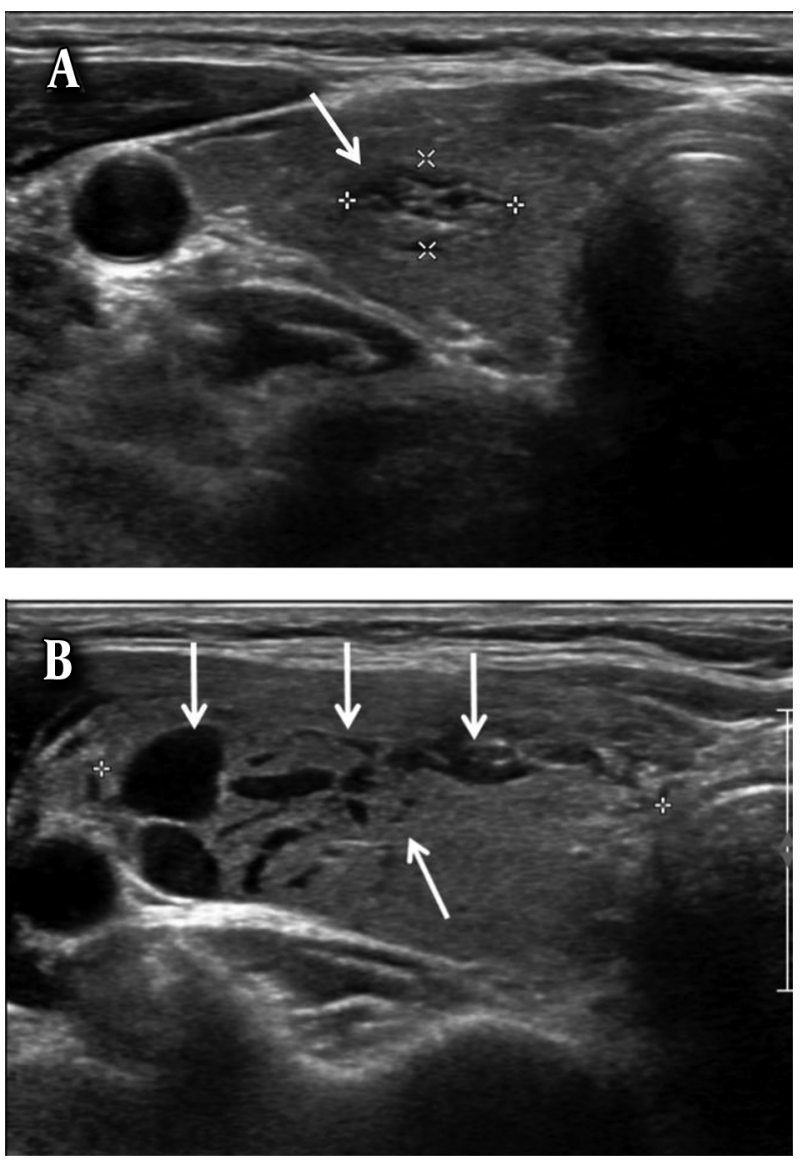

Figure 2. A 59-year-old woman with an intra-parenchymal hematoma. A, Axial ultrasonography image shows a solid nodule with spongiform appearance (arrow) in the right lobe of the thyroid gland. B, Axial ultrasonography image of the nodule af ter ultrasound-guided fine needle aspiration (US-FNA) shows the intra-parenchymal hemorrhage in the right lobe of the thyroid gland showing multiple linear-shaped anechoic lesions (arrows). The size of the right lobe of the thyroid gland is increased after US-FNA due to intra-parenchymal hemorrhage.

aPTT were performed before US-FNA of thyroid nodules. Thus, there is a possibility of hidden hematological abnormalities that may have influenced the hemorrhagic complications after US-FNA (5). Third, medical conditions affecting the coagulation status, such as chronic liver disease and hematological disease, could not be evaluated due to limited data. Fourth, late hematoma formation was not evaluated by US. Finally, we cannot evaluate the exact dose of the anticoagulant or antithrombotic agent in patients taking medications because more than half of the patients taking these medications obtain their prescriptions from outside the hospital.

In conclusion, males and a medical history of chronic renal failure were factors related to an increased incidence of hemorrhagic complications. US-FNA may be performed safely in patients taking anticoagulant or antithrombotic
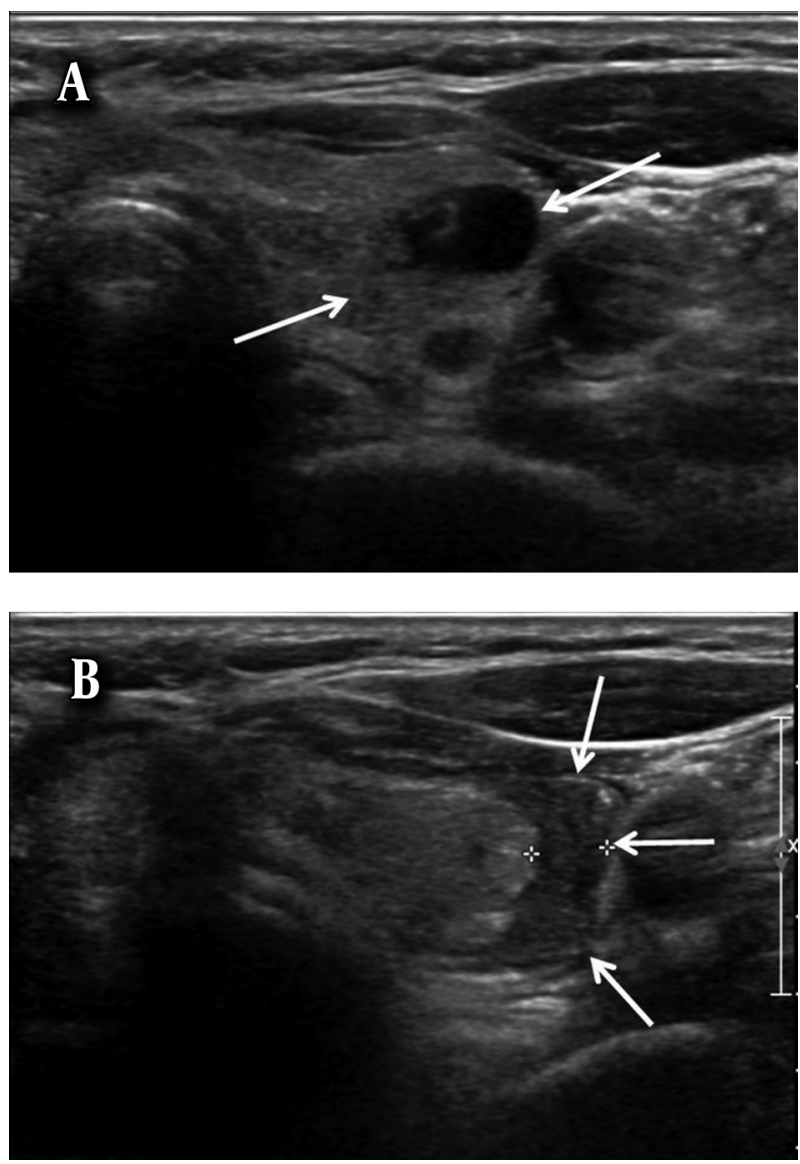

Figure 3. A 66-year-old woman with a subcapsular hematoma. A, Axial ultrasonography image shows a predominantly cystic nodule (arrows) in the left lobe of the thyroid gland. B, Axial ultrasonography image of the nodule after ultrasound-guided fine needle aspiration (US-FNA) shows a crescent-shaped hypoechoic subcapsular hematoma (arrows).

medications without stopping the medication. Large size, cystic or predominantly cystic internal content, benign US features of the thyroid nodules, use of a thicker nodule and a greater number of needle passes are related to an increased incidence of hemorrhagic complications.

\section{Acknowledgments}

None.

\section{Footnotes}

Authors' Contributions: This study was designed by Jae Hyun Kwon and Yoon Ki Cha Jeung Sook Kim. The study data were collected by Jae Hyun Kwon, Yoon Hee Han, and Dae Bong Kim. Ultrasography and US-FNA were performed by Jae Hyun Kwon, Yoon Hee Han, and Dae Bong 
Kim. Analysis and interpretation of data and drafting of the manuscript were performed by Jae Hyun Kwon and Yoon Ki Cha Jeung Sook Kim. Study supervision was performed by Jae Hyun kwon, Jeung Sook Kim and Dae Bong Kim.

Conflict of Interest: The authors declare that they have no conflict of interest.

Financial Disclosure: None to disclose.

\section{References}

1. Polyzos SA, Kita M, Avramidis A. Thyroid nodules - stepwise diagnosis and management. Hormones (Athens). 2007;6(2):101-19. doi: 10.14310/horm.2002.111107. [PubMed: 17704042].

2. Kim MJ, Kim EK, Park SI, Kim BM, Kwak JY, Kim SJ, et al. USguided fine-needle aspiration of thyroid nodules: indications, techniques, results. Radiographics. 2008;28(7):1869-86. discussion 1887. doi:10.1148/rg.287085033. [PubMed: 19001645].

3. Moon WJ, Baek JH, Jung SL, Kim DW, Kim EK, Kim JY, et al. Ultrasonography and the ultrasound-based management of thyroid nodules: consensus statement and recommendations. Korean J Radiol. 2011;12(1):114. doi:10.3348/kjr.2011.12.1.1. [PubMed: 21228935].

4. Polyzos SA, Anastasilakis AD. Clinical complications following thyroid fine-needle biopsy: a systematic review. Clin Endocrinol (Oxf). 2009;71(2):157-65. doi: 10.1111/j.1365-2265.2009.03522.x. [PubMed: 19170717].

5. Lee YH, Baek JH, Jung SL, Kwak JY, Kim JH, Shin JH, et al. Ultrasoundguided fine needle aspiration of thyroid nodules: a consensus statement by the korean society of thyroid radiology. Korean J Radiol. 2015;16(2):391-401. doi: 10.3348/kjr.2015.16.2.391. [PubMed: 25741201].

6. Polyzos SA, Anastasilakis AD. Systematic review of cases reporting blood extravasation-related complications after thyroid fine-needle biopsy. J Otolaryngol Head Neck Surg. 2010;39(5):532-41. [PubMed: 20828516].

7. Ogilvie JB, Piatigorsky EJ, Clark OH. Current status of fine needle aspiration for thyroid nodules. Adv Surg. 2006;40:223-38. doi: 10.1016/j.yasu.2006.06.003. [PubMed: 17163105].

8. Pitman MB, Abele J, Ali SZ, Duick D, Elsheikh TM, Jeffrey RB, et al. Techniques for thyroid FNA: a synopsis of the National Cancer Institute Thyroid Fine-Needle Aspiration State of the Science Conference. Diagn Cytopathol. 2008;36(6):407-24. doi: 10.1002/dc.20829. [PubMed: 18478608].

9. Cibas ES, Alexander EK, Benson CB, de Agustin PP, Doherty GM, Faquin WC, et al. Indications for thyroid FNA and pre-FNA requirements: a synopsis of the National Cancer Institute Thyroid FineNeedle Aspiration State of the Science Conference. Diagn Cytopathol. 2008;36(6):390-9. doi: 10.1002/dc.20827. [PubMed: 18478607].

10. Degirmenci B, Haktanir A, Albayrak R, Acar M, Sahin DA, Sahin O, et al. Sonographically guided fine-needle biopsy of thyroid nodules: the effects of nodule characteristics, sampling technique, and needle size on the adequacy of cytological material. Clin Radiol. 2007;62(8):798803. doi: 10.1016/j.crad.2007.01.024. [PubMed: 17604771].

11. Crockett JC. The thyroid nodule: fine-needle aspiration biopsy technique. J Ultrasound Med. 2011;30(5):685-94. doi: 10.7863/jum.2011.30.5.685. [PubMed: 21527617].

12. Rausch P, Nowels K, Jeffrey RJ. Ultrasonographically guided thyroid biopsy: a review with emphasis on technique. J Ultrasound Med. 2001;20(1):79-85. [PubMed: 11149534].

13. Suen KC. Fine-needle aspiration biopsy of the thyroid. CMAJ. 2002;167(5):491-5. [PubMed: 12240817].

14. Wu $\mathrm{M}$, Burstein $\mathrm{DE}$. Fine needle aspiration. Cancer Invest 2004;22(4):620-8. doi: 10.1081/CNV-200027160. [PubMed: 15565819].
15. Gharib H, Papini E, Valcavi R, Baskin HJ, Crescenzi A, Dottorini ME, et al. American Association of Clinical Endocrinologists and Associazione Medici Endocrinologi medical guidelines for clinical practice for the diagnosis and management of thyroid nodules. Endocr Pract. 2006;12(1):63-102. doi: 10.4158/EP.12.1.63. [PubMed: 16596732].

16. Abu-Yousef MM, Larson JH, Kuehn DM, Wu AS, Laroia AT. Safety of ultrasound-guided fine needle aspiration biopsy of neck lesions in patients taking antithrombotic/anticoagulant medications. Ultrasound Q. 2011;27(3):157-9. doi: 10.1097/RUQ.ob013e31822b5681. [PubMed: 21873852].

17. Lyle MA, Dean DS. Ultrasound-guided fine-needle aspiration biopsy of thyroid nodules in patients taking novel oral anticoagulants. Thyroid 2015;25(4):373-6. doi: 10.1089/thy.2014.0307. [PubMed: 25584817].

18. Jaffe TA, Raiff D, Ho LM, Kim CY. Management of Anticoagulant and Antiplatelet Medications in Adults Undergoing Percutaneous Interventions. AJR Am J Roentgenol. 2015;205(2):421-8. doi: 10.2214/AJR.14.13342. [PubMed: 26204296].

19. Tamsel S, Demirpolat G, Erdogan M, Nart D, Karadeniz M, Uluer H, et al. Power Doppler US patterns of vascularity and spectral Doppler US parameters in predicting malignancy in thyroid nodules. Clin Radiol. 2007;62(3):245-51. doi: 10.1016/j.crad.2006.10.003. [PubMed: 17293218].

20. Rago T, Vitti P, Chiovato L, Mazzeo S, De Liperi A, Miccoli P, et al. Role of conventional ultrasonography and color flow-doppler sonography in predicting malignancy in 'cold' thyroid nodules. Eur J Endocrinol. 1998;138(1):41-6. doi: 10.1530/eje.0.1380041. [PubMed: 9461314].

21. Frates MC, Benson CB, Doubilet PM, Cibas ES, Marqusee E. Can color Doppler sonography aid in the prediction of malignancy of thyroid nodules? J Ultrasound Med. 2003;22(2):127-31. quiz 132-4. doi: 10.7863/jum.2003.22.2.127. [PubMed: 12562117].

22. Stacul F, Bertolotto M, De Gobbis F, Calderan L, Cioffi V, Romano A, et al. US, colour-Doppler US and fine-needle aspiration biopsy in the diagnosis of thyroid nodules. Radiol Med. 2007;112(5):751-62. doi: 10.1007/s11547-007-0178-9. [PubMed: 17657415].

23. Moon HJ, Kwak JY, Kim MJ, Son EJ, Kim EK. Can vascularity at power Doppler US help predict thyroid malignancy? Radiology. 2010;255(1):260-9. doi: 10.1148/radiol.09091284. [PubMed: 20308462].

24. American Thyroid Association Guidelines Taskforce on Thyroid N, Differentiated Thyroid C, Cooper DS, Doherty GM, Haugen BR, Kloos RT, et al. Revised American Thyroid Association management guidelines for patients with thyroid nodules and differentiated thyroid cancer. Thyroid. 2009;19(11):1167-214. doi: 10.1089/thy.2009.0110. [PubMed: 19860577].

25. Gharib H, Papini E, Paschke R, Duick DS, Valcavi R, Hegedus L, et al. American Association of Clinical Endocrinologists, Associazione Medici Endocrinologi, and EuropeanThyroid Association Medical Guidelines for Clinical Practice for the Diagnosis and Management of Thyroid Nodules. Endocr Pract. 2010;16 Suppl 1:1-43. doi: 10.4158/10024.GL. [PubMed: 20497938].

26. Cappelli C, Pirola I, Castellano M, Gandossi E, De Martino E, Delbarba A, et al. Fine needle cytology of complex thyroid nodules. EurJEndocrinol. 2007;157(4):529-32. doi: 10.1530/EJE-07-0172. [PubMed: 17893269].

27. Khoo TK, Baker CH, Hallanger-Johnson J, Tom AM, Grant CS, Reading $\mathrm{CC}$, et al. Comparison of ultrasound-guided fine-needle aspiration biopsy with core-needle biopsy in the evaluation of thyroid nodules. Endocr Pract. 2008;14(4):426-31. doi: 10.4158/EP.14.4.426. [PubMed: 18558594].

28. Newkirk KA, Ringel MD, Jelinek J, Mark A, Wartofsky L, Deeb $\mathrm{ZE}$, et al. Ultrasound-guided fine-needle aspiration and thyroid disease. Otolaryngol Head Neck Surg. 2000;123(6):700-5. doi: 10.1067/mhn.2000.110958. [PubMed: 11112961].

29. Silverman JF, West RL, Larkin EW, Park HK, Finley JL, Swanson MS, et al. The role of fine-needle aspiration biopsy in the rapid diagnosis and management of thyroid neoplasm. Cancer.1986;57(6):1164-70. [PubMed: 3943039]. 
30. Hor T, Lahiri SW. Bilateral thyroid hematomas after fine-needle aspiration causing acute airway obstruction. Thyroid. 2008;18(5):567-9. doi: 10.1089/thy.2007.0363. [PubMed: 18397159].

31. Roh JL. Intrathyroid hemorrhage and acute upper airway obstruction after fine needle aspiration of the thyroid gland. Laryngoscope. 2006;116(1):154-6. doi: 10.1097/01.mlg.0000187396.18016.do. [PubMed: 16481831].

32. Braga M, Cavalcanti TC, Collaco LM, Graf H. Efficacy of ultrasoundguided fine-needle aspiration biopsy in the diagnosis of complex thyroid nodules. J Clin Endocrinol Metab. 2001;86(9):4089-91. doi 10.1210/jcem.86.9.7824. [PubMed: 11549630].

33. Patel IJ, Davidson JC, Nikolic B, Salazar GM, Schwartzberg MS, Walker TG, et al. Consensus guidelines for periprocedural management of coagulation status and hemostasis risk in percutaneous imageguided interventions. J Vasc Interv Radiol. 2012;23(6):727-36. doi 10.1016/j.jvir.2012.02.012. [PubMed: 22513394].

34. Park MH, Yoon JH. Anterior neck hematoma causing airway compression following fine needle aspiration cytology of the thyroid nod ule: a case report. Acta Cytol. 2009;53(1):86-8. doi: 10.1159/000325089. [PubMed: 19248559].

35. Baloch ZW, Cibas ES, Clark DP, Layfield LJ, Ljung BM, Pitman MB, et al. The National Cancer Institute Thyroid fine needle aspiration state of the science conference: a summation. Cytojournal. 2008;5:6. doi 10.1186/1742-6413-5-6. [PubMed: 18394201].

36. Redman R, Zalaznick H, Mazzaferri EL, Massoll NA. The impact of as- sessing specimen adequacy and number of needle passes for fineneedle aspiration biopsy of thyroid nodules. Thyroid. 2006;16(1):5560. doi:10.1089/thy.2006.16.55. [PubMed: 16487014]

37. Layfield LJ, Cibas ES, Gharib H, Mandel SJ. Thyroid aspiration cytology: current status. CA Cancer J Clin. 2009;59(2):99-110. doi: 10.3322/caac.20014. [PubMed: 19278960].

38. Mair S, Dunbar F, Becker PJ, Du Plessis W. Fine needle cytology-is aspiration suction necessary? A study of 100 masses in various sites. Acta Cytol.1989;33(6):809-13. [PubMed: 2488680].

39. Kate MS, Kamal MM, Bobhate SK, Kher AV. Evaluation of fine needle capillary sampling in superficial and deep-seated lesions. An analysis of 670 cases. Acta Cytol. 1998;42(3):679-84. doi: 10.1159/000331826. [PubMed: 9622687].

40. Pothier DD, Narula AA. Should we apply suction during fine needle cytology of thyroid lesions? A systematic review and meta-analysis. Ann R Coll Surg Engl.2006;88(7):643-5. doi:10.1308/003588406X149147. [PubMed: 17132312].

41. Titton RL, Gervais DA, Boland GW, Maher MM, Mueller PR. Sonography and sonographically guided fine-needle aspiration biopsy of the thyroid gland: indications and techniques, pearls and pitfalls. AJR Am J Roentgenol. 2003;181(1):267-71. doi: 10.2214/ajr.181.1.1810267. [PubMed: 12818871].

42. Miller JM, Zafar SU, Karo JJ. The cystic thyroid nodule. Recognition and management. Radiology. 1974;110(2):257-61. doi: 10.1148/110.2.257. [PubMed: 4810134]. 